\title{
Parallel Imports, Innovations and National Welfare Role of the Sizes of the Income Classes and National Markets for Health Care
}

\author{
Rajat Acharyya* \\ Jadavpur University \\ and \\ María D. C. García-Alonso \\ University of Kent
}

Revised Draft: July 2007

Key Words: Parallel Imports; Price Discrimination; Health-Care Innovation; Market size; Income Distribution.

JEL Cl. Nos.: F13, I1 1, O34

\footnotetext{
- An earlier version of this paper was presented at the ERGICHCS Conference on Innovation and Change in Health Care Systems held at the Andrassy University, Budapest, during 10-12 May, 2007. Rajat Acharyya would like to thank Martina Eckardt, Stefan Okruch, Carsten Hermann-Pillath and other conference participants for their useful comments. The usual disclaimer applies, however.

- Corresponding author. Department of Economics, Jadavpur University. Calcutta 700 032, India, e-mail: racharya@cal2.vsnl.net.in.
} 


\section{Introduction}

This paper examines the implications of parallel trade for the level of innovations in health care market, the price of the innovated drug and for the welfare levels of the Third and the Rich world. These implications are drawn in terms of both the size of the Third-world and the Rich-world markets relative to the differences in their per capita income levels and the distribution of potential buyers in each market over different income levels.

Possibly the most researched example of the impact of parallel trade on market access to drugs is that of the AIDS drugs. This is not surprising given that they have become the object of numerous international initiatives such as the Global Fund aimed at transferring income to poorer nations so as to increase their purchasing power for medicines. Although the Global Fund also covers Tuberculosis and Malaria, the idea that parallel imports may affect market is not so relevant in those cases. The reason is that, unlike AIDS, Tuberculosis and Malaria are mostly prevalent only in low income countries and therefore, the higher income countries are unlikely to represent a significant proportion of the demand for the medicines targeting such illness. Hence, richer countries are not likely to drive out supply to lower income countries in the presence of price arbitrage ${ }^{1}$.

The importance of parallel imports on the pricing strategies of AIDS drugs is well documented. For instance, Scherer and Watal (2002), and Hornbeck (2005) show that there is little statistical evidence of income based price discrimination in AIDS drugs across countries. They both suggest increasing the barriers to parallel trade as a way to increase well-being of poorer nations. However, as Rovira (2002) points out, it is sometimes too simplistic to just think of rich and poor countries in the world as the key to increasing access to medicines. Issues such as the scope and extent of coverage provided by national health systems become relevant especially in the presence of intracountry income inequality. Indeed, Hornbeck (2005) hints that there might be some link between intra-country inequality and the pricing of AIDS drugs. This strategic aspect of pricing raises the

\footnotetext{
${ }^{1}$ Note this does not mean that the development and access to say malaria vaccines is not a challenge. It just posses different problems, more specifically, a public procurement problem as in those cases the market demand (due to low purchasing power) is just not strong enough to provide enough incentives for pharmaceutical firms to develop innovative drugs.
} 
issue of how not just different countries but, also different income groups within each country are affected by the ability of firms to implement international price discrimination.

The markets in different countries that differ with respect to willingness-to-pay for internationally traded commodities create scope as well as incentive for the MNCs having monopoly rights over their patented range of products to price discriminate. But, parallel trading limits the extent to which such price discrimination is feasible (and profitable). Rules of internal market in the EU allows parallel trade of any on-patent product, by which any trading firm can purchase such goods from the market supplied by the patent holding manufacturer and sell them in any other market without requiring the consent of the patent holder. Allowing for parallel trade as the rule of internal market in the EU emerged out of the Treaty of Rome and has found endorsement in the European Court of Justice that held that a patent holder's rights are exhausted EU-wide once the on-patent product is placed anywhere in the EU market. Parallel imports (and external referencing) especially of drugs are now being allowed in many other countries. For example, the new legislation in South Africa allows her health minister to resort to parallel imports if an on-patent drug is sold at a very high price [Maskus (2001)]. This has become the bone of contention triggering countless debates on who gains from such parallel trading. Danzon (1998) has been severely critical of the rationale of such a policy arguing strongly that this will in fact increase the price of imported drugs in the low-income countries and lower welfare all around.

Parallel imports restrict the patent holder's ability to discriminate among different markets on the basis of persisting income differences. If volumes of parallel imports are sufficiently high, the patent holder firm is forced to charge a uniform price in all markets related through trade. The only difference in prices across markets that might still exist would simply reflect differences in transport costs and different country-specific rates of tariffs. By the conventional wisdom of standard economic theory, the uniform price will be set somewhere between the highest and lowest discriminatory prices. Of course, as pointed out by Maskus (2001) and Jelovac and Bordoy (2005), there can be complete price convergence (or global uniform pricing) only if consumers value the original and parallel imported drugs equally. But this may not be the case because of different packages or guarantees. In general, however, under parallel imports, some of the low-income countries will experience an increase in the prices of drugs after parallel trading, and even worse, 
they may simply be priced out of the market, thus losing access to new drugs [Danzon (1998), Maskus (2001), Malueg and Schwartz (1994)]. This is now a major concern and the origin of an ongoing debate on how to ensure Third World access to new innovated drugs, as low discriminatory prices can no longer be charged in these markets, and a low uniform price, as the pharmaceutical MNCs argue, cannot cover the costs of $R \& \mathrm{D}^{2}$.

The price convergence under parallel trading may also entail welfare losses for the poorer countries even when all these countries are served, whereas it may bring in gains for the richer countries. Jelovac and Bordoy (2005) have found an improvement in the total welfare when the countries differ only in their drug needs but a decline when they have different health insurance reimbursement policies. In addition to these static losses, there are some dynamic (or long term) losses as well. The lower profits for the multinational pharmaceutical companies may in fact lower their incentives to develop new drugs that involve substantial R\&D costs. Of late, Valletti (2006) has precisely argued along this line in a model of vertical product differentiation with the marginal willingness-to-pay for the innovated quality of a drug varying both within and across the countries. In particular, he finds that a patent holder firm will invest less in product-R\&D and develop a lower quality variety of a drug under parallel imports than it would have done in the absence of such a rule of internal market. But, for some extreme parametric values, he finds an improvement in the global welfare under parallel importing.

However, the improvement in global welfare is less appealing if it is associated with a fall in consumers' surplus in the low-income countries. So it is worthwhile to know the country-specific welfare properties of parallel trading that depend on the direction of the consequent changes in both the price and the level of $R \& D$ investment. This country-specific welfare effect is an important determinant of parallel trade as a policy choice of the trading nations behaving non-cooperatively. For example, Richardson (2002) has demonstrated that when countries can individually choose whether or not to allow parallel imports, the unique Nash equilibrium is the one where all countries that are served permit parallel importing. This is because the high-price countries that benefit from

\footnotetext{
${ }^{2}$ The Global Fund launched by the UN has been driven primarily by this cause of concern. See Acharyya and GarciaAlonso (2006) for a discussion on how such a cash transfer programme, even under parallel imports, can induce innovation of drugs. Moreover, such innovations provide a self-interested motive for buyers in the rich countries to participate voluntarily in such Global Fund programme.
} 
parallel imports can undo price discrimination. This results in global uniform pricing ${ }^{3}$. Of course, this result depends on the inability of the low-price countries to restrict parallel exports of the drug to the high-price countries. But when the countries can simultaneously choose parallel imports and exports policies, (market-based) price discrimination will be the Nash equilibrium outcome. However, his analysis is based on only the static price and output effects of parallel imports on country-specific welfare. It is to be seen, therefore, what implications does the under-investment result have on the country-specific welfare levels and consequently on the individual decisions of the trading nations regarding whether to allow or prohibit parallel trade.

Given such specific concerns, our analysis differs from that of Valletti (2006) in one important direction. We take into account the intra-country non-uniform income distributions and physical size differences of the countries in addition to their difference in the maximum willingness-to-pay for the innovated drug. Though the under-investment result still holds, under full market coverage the uniform price under parallel imports is smaller than the discriminatory prices. As we demonstrate here, whether all the markets and all the consumers in each market will be covered under parallel imports or not depends on the inter and intra country income distribution pattern in relation to the (relative) degree of the per-capita income differences of the countries. When it is profitable for the patent-holder firm to serve all the markets and consumers, parallel imports unambiguously lowers the (uniform) price of the innovated drug below the lowest discriminatory price. This is because under full market coverage, under-investment and thus development of a lower quality drug must be accompanied by a reduction in its price to induce all consumers to buy the innovated drug. This result is important and, in fact, rationalizes the apprehension underlying the South African legislation modification that discriminatory prices may result in higher domestic prices of imported drugs. By implicitly assuming all markets that are served are partially covered by the MNC, Valletti (2006) ignores this possibility of the uniform price under parallel imports being lower in all countries including the country with the lowest price under discrimination. But as demonstrated by Wauthy (1996) and Acharyya (1998), the extent of market coverage should be an equilibrium outcome of the profit-maximizing behaviour of firm(s) rather than an ex ante restriction.

\footnotetext{
${ }^{3}$ But if governments have political economy concerns, then even high-price countries may choose to prohibit parallel imports [Richardson (2002, p. 242)].
} 
Yet, consumers in the low-income countries lose under parallel trading because the price decline does not compensate them for the under-investment in $R \& D$ that results in development of a lower quality drug compared to the discriminatory regime. Thus, observation by Maskus (2001) that "it is curious that most developing countries express opposition to restricting parallel trade" is correct but for different reasons ${ }^{4}$. These oppositions to restrict parallel trade are hard to justify not because parallel imports would actually result in higher prices of drugs, but because it would lead to underinvestment in innovations resulting in a poor quality of life and loss of welfare.

We also find that only the very rich buyers in the rich world may gain because for them the uniform pricing under parallel imports brings in a large decline in the price of the new drug that may overcompensate its utility loss from the low level of innovation. But if the patent-holder MNC belongs to the rich world and its lower profit is taken into account, total welfare of the rich country unambiguously falls. Thus, parallel trading does not bring any welfare gain at all. Both the countryspecific and the global welfare levels decline unambiguously. This means that when the R\&D effect is also taken into account, even the high-price countries may prefer discrimination. Indeed, once we allow for intra-country income inequality, even discarding the MNC's profit, there will be cases in which the richer country prefers price discrimination as well. That is, in those cases no countries will have any incentive under the welfare criterion to undo price discrimination. Thus, the first result of Richardson (2002) is invalidated whereas his second result (viz. price discrimination as the equilibrium choice of countries) extends to the R\&D case even when the low-price countries cannot restrict parallel exports.

Our results can also be related to Malueg and Schwartz (1994), though, unlike Malueg and Schwartz (1994), we are concerned with the impact of parallel imports on the different consumer groups and not aggregate welfare. However, for the case of no intra-country income inequality, it is straightforward to compare the welfare levels with and without parallel imports. What we find out is that price discrimination is then good for welfare even if no markets are dropped as a result of parallel imports. This result is partially due to the lower optimal quality with parallel imports and contrasts with Malueg and Schwartz (1994). Still, the main driver of the result in their paper is that uniform pricing improves allocative efficiency. That effect is not present in our paper since the

\footnotetext{
${ }^{4}$ See Abbott (1998).
} 
demands are unitary and the firm will always set a price that will make all rich consumers buy, and therefore, any changes in price will just imply a transfer of surplus between consumer and producer without deadweight loss.

Our paper suggests an alternative interpretation of our assumption of intra-country inequality. We consider a world with blocks of countries with different incomes (a developed block and a developing block) that may or may not allow parallel imports across or within the block itself. This case is relevant to the current discussions on patent protection and price arbitrage within the context of WTO trade negotiations and the existence of free trade zones such us the EU.

The preference structure used to demonstrate the above-mentioned results is drawn heavily from the self-selection model developed in Cooper (1984) and Acharyya $(1998,2005)^{5}$. Two different cases are discussed. In the first case, there is no intra-country but only inter-country income differences. This case is studied to capture the implications of the relative size of countries differing in terms of their per capita income. In the second case, we allow for intra-country income disparity to demonstrate that under certain parametric restrictions on the distribution pattern in the rich world, the very rich consumers may benefit from parallel trading.

The rest of the paper is organized as follows. In section 2 we consider the benchmark case of per capita income differences of the countries with no intra-country income disparity. Section 3 examines the welfare properties of parallel imports when intra-country income disparity exists. A re-interpretation of the model to study regional exhaustion, instead of global exhaustion, of property rights is provided in section 4 . Finally, we conclude the paper in section 5 .

\section{Health Care Innovation in a Two-Country World Economy}

Consider a world economy with two countries: a poor country or a Third World $(\mathrm{T})$ and a rich country (R). To begin with, consider inter-country income differences but no intra-country income disparity. Let the per capita income levels be $y_{T}$ and $y_{R}$, and the number of consumers be $n_{T}$ and $n_{R}$ in the Third and the rich world respectively. Consumers in each country have identical valuations $\theta$

\footnotetext{
${ }^{5}$ These analyses examine the choice of a monopolist over a separating and a pooling (or uniform) price-quality menu for heterogeneous consumers in a market without any threat from imports. For a related earlier work, see Mussa and Rosen (1978).
} 
for a particular quality of the drug that is being developed by a pharmaceutical MNC. This valuation is assumed to be linearly related to the income level. Each consumer buys, if at all, only one unit of the drug. Thus a representative consumer in country- $j, j=T, R$, derives (gross) utility from buying a drug of quality $s$ as:

$$
U_{j}=u\left(y_{j}, s\right)
$$

that increases at a decreasing rate with the higher quality of the drug:

$$
u_{s}>0, u_{s s} \leq 0
$$

By our assumption, since $y_{T}<y_{R}$, so,

$$
u\left(y_{T}, s\right)<u\left(y_{R}, s\right) \forall s
$$

Thus, a rich-world buyer derives greater utility than a Third-world buyer from the same quality drug. Moreover, following the literature on quality choice, it is reasonable to assume that a richworld buyer has a greater addition to his utility and hence would be willing to pay more at the margin for a better quality drug that is innovated than a Third-world buyer would like to:

$$
\frac{\partial u\left(y_{R}, s\right)}{\partial s}>\frac{\partial u\left(y_{T}, s\right)}{\partial s} \forall s
$$

These restrictions on the preference function have been widely used in the parallel literature on quality choice with heterogeneous consumers [Mussa and Rosen (1978), Shaked and Sutton (1982), Cooper (1984), Acharyya $(1998,2005)]$.

To exemplify our results we assume a linear form of the utility function defined in (1):

$$
u\left(y_{j}, s\right)=y_{j} s
$$


This linear preference structure, however, does not alter our results qualitatively. Note that (1a) satisfies all the desirable properties as specified in (2) - (4). Let the reservation utility of a buyer of income $y_{j}$ be zero. Thus, by the individually rational (IR) constraint, he buys the drug if,

$$
y_{j} s \geq P
$$

There is a single pharmaceutical MNC situated in the rich country that plans to develop a new drug of quality $s$ by investing the amount $C$ in $\mathrm{R} \& \mathrm{D}$. This $\mathrm{R} \& \mathrm{D}$ investment is increasing at an increasing rate in the target level of quality of the innovated drug:

$$
C=\frac{1}{2} s^{2}
$$

Except for this sunk cost, there is no other cost. Once the drug is developed, the MNC gets a patent that confers it with a monopoly right over its exclusive sales in different markets. Given the income differences across the rich and the Third world, such monopoly right creates scope for marketbased (price) discrimination (MBD) for the MNC. However, its ability to discriminate may be limited by parallel trading allowed by the countries. The MNC's innovation level and pricing of the drug thus vary according to whether parallel imports are allowed or not. In the following subsections, we consider investment decisions and welfare properties under each of these two regimes. The choices under the MBD regime are denoted by subscript $D$, whereas those under parallel imports are denoted by subscript $P I$.

\subsection{Health Care Innovation under MBD}

Given the IR constraint in (5), for any innovated quality of the drug, under the MBD regime the MNC extracts all surpluses from the consumers in each country by charging $P_{j D}=y_{j} s, j=R, T$. Thus, the profit realized equals,

$$
\pi_{\mathrm{D}}=\left(n_{T} \mathrm{y}_{\mathrm{T}}+n_{R} \mathrm{y}_{\mathrm{R}}\right) \mathrm{S}_{\mathrm{D}}
$$


The MNC decides about the quality level of the innovated drug and corresponding R\&D investment level by maximizing this ex post (or realized) profit net of the R\&D cost:

$$
\pi\left(s_{D}\right)=\left(n_{\mathrm{T}} \mathrm{y}_{\mathrm{T}}+n_{\mathrm{R}} \mathrm{y}_{\mathrm{R}}\right) s_{D}-\frac{1}{2} s_{D}^{2}
$$

The first-order condition yields the following choice of quality level and corresponding investment level:

$$
s_{D}^{e}=n_{\mathrm{T}} \mathrm{Y}_{\mathrm{T}}+n_{\mathrm{R}} \mathrm{Y}_{\mathrm{R}}
$$

The corresponding equilibrium prices are:

$$
P_{D j}^{e}=\left(n_{\mathrm{T}} \mathrm{y}_{\mathrm{T}}+n_{\mathrm{R}} \mathrm{y}_{\mathrm{R}}\right) \mathrm{y}_{j}, j=T, R
$$

Note that both the innovated quality of the drug and its market-specific (discriminatory) prices depend on the income levels as well as on the size of the markets.

Since all surpluses are extracted by the MNC from both the rich and the poor consumers, the consumers' surplus in each country is zero, and the welfare of the rich country equals the profit of the MNC under MBD.

\subsection{Parallel Imports}

When parallel imports and exports are allowed by the two countries, the traders buy the drug in the low-priced Third World and export it to the high-priced Rich world. Thus, assume that the Third World government allows parallel exports and the rich world government allows parallel imports of the innovated drug. These policies limit the patent-holder MNC's ability to discriminate between the two countries. The MNC can still charge differential pricing if it offers limited geographical warranty for the innovated drug. Since the parallel traders cannot provide warranty coverage for the parallel exported drugs to the rich world, the buyers in the rich world would value these drugs less than the one sold by the MNC to them. Thus, as argued by Jelovac and Bordoy (2005) and Maskus (2001), even under parallel trading the prices need not be the same in the two markets. To illustrate, let $\beta<1$ be the rate at which buyers in the rich world discount the value of the drug re-exported 
under parallel trading. Thus, the net utility that a representative rich-world buyer receives from buying the low-priced drug imported from the Third World equals,

$$
V\left(y_{R}, S\right)=\beta y_{R} \mathrm{~S}-y_{T} \mathrm{~S}
$$

where, $S$ is the perceived quality of the parallel imported drug.

If the MNC charges the price $p_{R}$ to him, he buys it if $V\left(y_{R}, s\right) \geq V\left(y_{R}, S\right)$, i.e., if,

$$
p_{R} \leq y_{T} \mathrm{~s}+(1-\beta) y_{R} \mathrm{~S}
$$

Thus, for $\beta<1$, the MNC can charge a higher price than the price $y_{T} \mathrm{~s}$ at which the innovated drug is sold by it in the Third World and re-exported to the rich world by the parallel traders. But if there is no geographical warranty and other reasons for the rich-world buyers to differentiate between the drug sold by the MNC and the one re-exported by parallel traders (i.e., $\beta=1$ ), parallel trading will erode all price differences across these two markets. In rest of the analysis, however, we shall assume that the buyers do not discount the re-exported drug so that under PI the monopolist must charge uniform price in all the markets. For drugs that are search goods in nature in the terminology of Nelson (1974) - whose quality is known to the buyers a priori - like the one modeled here (and in the existing literature), warranty does not make much of a sense and thus discounted valuation of the parallel imported drugs needs to be justified differently ${ }^{6}$.

Given the (per capita) income differences of the countries, there are two possible (uniform) prices for any innovated quality. One is charging $y_{\mathrm{R}} S$ and thus excluding the Third world buyers from accessing the innovated drug. This is the case of partial coverage of the global (or integrated) market. Equilibrium choices under this partial coverage are denoted by tilde over the choice variables. The other is charging the lower uniform price $y_{\mathrm{T} S}$, which is the case of full (global) market coverage.

\footnotetext{
${ }^{6}$ The geographical warranty story is more relevant for durable pharmaceutical products like surgical instruments, sphygmomanometer, medical testing kits and the like, but not so much perhaps for drugs.
} 
Proceeding as before, it is straightforward to check the following two quality levels under partial and full market coverage:

$$
\begin{aligned}
& \tilde{s}_{P I}^{e}=n_{R} y_{R} \\
& s_{P I}^{e}=\left[n_{T}+n_{R}\right] y_{T}
\end{aligned}
$$

Thus the choice of the market coverage under PI depends on the size of the two countries. More precisely,

Lemma 1: The MNC caters to both the markets under PI only if $\frac{n_{T}}{n_{R}}>\frac{y_{R}-y_{T}}{y_{T}}$.

Proof: Given (11a) and (11b), the profits from serving only the rich world and from serving both the markets are respectively,

$$
\begin{aligned}
& \tilde{\pi}_{P I}=\frac{1}{2}\left(n_{R} y_{R}\right)^{2} \\
& \pi_{P I}=\frac{1}{2}\left[\left(n_{T}+n_{R}\right) y_{T}\right]^{2}
\end{aligned}
$$

Thus, $\pi_{P I}>\tilde{\pi}_{P I}$ if $\left(n_{T}+n_{R}\right) y_{T}>n_{R} y_{R}$, which boils down to,

$$
\frac{n_{T}}{n_{R}}>\frac{y_{R}-y_{T}}{y_{T}}
$$

Hence the claim.

This is understandable. Only if the number of potential buyers in the Third world is sufficiently large in the sense defined in (12), it makes sense for the MNC to charge a lower uniform price $y_{\mathrm{T}} S$ to serve both the markets. Moreover, the larger is the income gap across the rich and the Third world, the greater should be the size of the market in the Third world to induce the MNC to cater to them. However, note that the loss of access to new drugs for the Third world under PI (when it is not sufficiently large in size in the sense defined in (12)) is because of the profit-maximizing motive of the MNC rather than the oft-quoted argument that the low uniform price that enables such access does not cover the cost of innovation. The policy implication of this result is that a small country (in the above sense) should not allow parallel exports of the drug to the rich world if it has to ensure access to the innovated drug for its own consumers. 
The interesting observation is that if serving all markets is profitable for the MNC, it develops a higher quality drug than when it caters only to the rich-world buyers. But in both these cases, regardless of the relative country sizes, PI leads to lower R\&D investment and innovation of lower quality drug than under MBD. Therefore,

Proposition 1: Parallel imports unambiguously lower health care innovation. The extent of such decline in the investment is larger for a relative size of the Third world smaller than that specified in (12).

Proof: The first part follows directly from the quality choices under MBD and PI as in (9), (11a) and (11b). For the second part, it is sufficient to note that $\widetilde{s}_{P I}=2\left(\tilde{\pi}_{P I}\right)^{\frac{1}{2}}$ and $s_{P I}=2\left(\pi_{P I}\right)^{\frac{1}{2}}$, so that for a relative size of the Third world smaller than that specified in (12), $s_{P I}^{e}>\tilde{s}_{P I}^{e}$.

\subsection{The Welfare Property of PI}

The relevant case for comparison of equilibrium prices and welfare levels under market-based discrimination and parallel import regimes is the one where both countries are served ${ }^{7}$. This confines us to the relative country sizes defined in (12). It is then straightforward to check that,

$$
P_{P I}^{e}-P_{D T}^{e}=n_{R}\left(y_{T}-y_{R}\right) y_{T}
$$

Therefore,

Lemma 2: Under parallel imports the poor country buyers get the innovated drug, albeit of lower quality, at a lower price than under market-based discrimination.

Proof: $\quad$ Since $y_{R}>y_{T}$, the result follows directly from (13).

\footnotetext{
${ }^{7}$ When only the rich world is served under PI, it unambiguously loses. As in case of MBD, the MNC extracts all the surpluses from the buyers there so that the social welfare of the rich world is just the MNC profit, which, however, is smaller under PI than under MBD.
} 
This is contrary to what Maskus (2001) argued, but of course is not counter-intuitive. When it is profitable for the MNC to serve the poor country, it must lower the price below the discriminatory price $P_{D T}^{e}$ to satisfy the IR constraint (5) of the buyers there since the innovated drug is now of a lower quality variety. That is, the uniform price under PI is lower than both the discriminatory prices because of the adverse dynamic (or R\&D) effect of PI that has been ignored Maskus and other researchers while discussing the effect on the drug prices. This result, in fact, can be stated in more general terms. As long as the marginal-willingness-to-pay for higher innovated quality differs across different countries, be it due to (per capita) income or taste or both, PI will lower the price of the drug all around, provided of course it is still profitable for the MNC to serve all markets as under $\mathrm{MBD}^{8}$.

Yet, the Third world does not gain. In fact it does not lose either because under both the marketbased discrimination and parallel import regimes the $\mathrm{MNC}$ extracts all surpluses from the consumers there. The rich-country buyers, on the other hand, unambiguously gain because the uniform pricing under parallel imports leaves them with a strictly positive net surplus. The loss of utility from the lower quality of health care is overcompensated by the large decline in the price that is required to induce the buyers in the poor-country to buy the innovated drug.

Regarding the rich country, it is worth noting that even though consumer surplus is higher with parallel imports (due to the lower price that compensates for the lower quality), once the MNC profits are added to welfare, the higher profits the MNC gets under MBD actually compensate for the lower consumer surplus thereby making MBD preferable for a rich country with a MNC ${ }^{9}$.

\subsection{International Redistribution of Income}

An interesting policy implication that follows from the above discussions is that an international redistribution of income from the rich to the poor world, such as the UN launched Global Fund,

\footnotetext{
${ }^{8}$ As pointed out by Tirole (1989), as long as the preference structure satisfies the properties specified above, the source of consumer heterogeneity (across or within countries) does not matter. For a more elaborate discussion on this see Acharyya (2005).

${ }^{9}$ Simply note that by Proposition 1 , $W_{D}^{R}-W_{P I}^{R}=n_{R} y_{R}\left(s_{D}^{e}-s_{P I}^{e}\right)+n_{T}\left(P_{D T}^{e}-P_{P I}^{e}\right)+\frac{1}{2}\left[\left(s_{P I}^{e}\right)^{2}-\left(s_{D}^{e}\right)^{2}\right]=\frac{1}{2} n_{R}\left(y_{R}-y_{T}\right)\left(s_{D}^{e}-s_{P I}^{e}\right)>0$.
} 
may induce higher innovation as well as access of the Third world to such innovation. Let $\hat{y}_{T}$ and $\hat{y}_{R}$ be the post-transfer income levels of consumers in the Third and the rich world respectively. Under the market-based discrimination, denoting the post-transfer innovation level as $s_{D F}$, using (9) we can write,

$$
s_{D}-s_{D F}=n_{R}\left(y_{R}-\hat{y}_{R}\right)-n_{T}\left(\hat{y}_{T}-y_{T}\right)
$$

But since in this two-country model, the total contribution by the rich country must equal the income received by the poor country, so $n_{R}\left(y_{R}-\hat{y}_{R}\right)=n_{T}\left(\hat{y}_{T}-y_{T}\right)$. Hence, $s_{D}=s_{D F}$. Thus, an international redistribution of income from the rich to the Third leaves the innovated quality of the drug unchanged.

Under parallel imports, on the other hand, such redistribution of income raises the innovation level when both the markets are served. This is evident from (11b). Moreover, since the right-hand-side value in (12) declines with such a transfer, transfers now make it profitable for the MNC to cater to even a smaller sized Third world. In other words, a transfer of income from the rich to the Third world ensures access to the innovated drugs and health care even for a smaller Third world. This result is similar to the one derived in Acharyya and Garcia-Alonso (2006).

\section{Intra-Country Income Differences and Health Care Innovation}

The intra-country income disparity, which has not been considered in the benchmark case discussed above, is often quite significant in the Third and the rich world. In this section, we examine how far do our results change in such a case.

There are several ways one can introduce intra-country income disparity in the basic framework of analysis. One simple and tractable way is to consider the discrete case where there are only two income levels in each country: $\bar{y}_{T}$ and $y_{M}$ in the Third world and, $y_{M}$ and $\bar{y}_{R}$ in the rich world, and $\bar{y}_{T}<y_{M}<\bar{y}_{R}$. Essentially this means that the two countries differ both in respect to the minimum and the maximum willingness-to-pay. We shall later discuss the implication of countries differing 
only in respect of the maximum willingness-to-pay as in Valletti (2006). Let $n_{T 1}, n_{T M}, n_{R M}$ and $n_{R 2}$ are the number of (potential) buyers in the respective income classes in the two countries. For the purpose of drawing implications of intra-country income disparity and distribution pattern per se, we make two assumptions. First of all, the country sizes are the same as before:

$$
\begin{aligned}
& n_{T 1}+n_{T M}=n_{T} \\
& n_{R M}+n_{R 2}=n_{R}
\end{aligned}
$$

Second, the national incomes of the countries remain the same. That is,

$$
\begin{aligned}
& n_{T 1} \bar{y}_{T}+n_{T M} y_{M}=n_{T} y_{T} \\
& n_{R M} y_{M}+n_{R 2} \bar{y}_{R}=n_{R} y_{R}
\end{aligned}
$$

Thus, given (15), $\bar{y}_{T}<y_{T}$ and $y_{R}<\bar{y}_{R}$.

\subsection{Single Price under Market-Based Discrimination}

Perfect price discrimination is no longer possible now even when parallel imports are not allowed. This is because a priori the exact type of a buyer in any market is not known to the MNC. For example, for any given choice of the innovated quality $s$, if in the rich world the MNC charges the poorer buyers with income $y_{M}$ the price $y_{M} s$ and the richer buyers with income $\bar{y}_{R}$ the price $\bar{y}_{R} s$, the expected profit $\left(n_{R M} y_{M}+n_{R 2} \bar{y}_{R}\right) s$ is never realized unless the MNC can identify who are the poorer and who are the richer buyers, and accordingly can prohibit the richer buyers from mimicking the poorer buyers. Thus, without parallel imports, the MNC is forced to charge uniform prices in each country, which, however, may differ across these national markets.

Under MBD, serving only one market is clearly profit reducing for the MNC since without parallel trading, there would be no arbitrage across the countries. The choice for the MNC is then whether to cater to all types in each market by charging a low uniform price, to only the richer buyers in the Third world but serving all in the rich world, to all in the Third world but only the richer buyers in the rich world, and finally, only the richer people in each country. The first one is what we call full 
market coverage whereas the other three possibilities are the different cases of partial market coverage. These choices of price and the extent of coverage of each market depend on the size of income classes or the pattern of intra-country income disparity in each country, similar to the condition (12). In particular,

Lemma 3: With intra-country income disparity, the patent-holder MNC serves all markets with full coverage under MBD if the income distribution pattern in each country satisfies,

$$
\begin{aligned}
& \frac{n_{T 1}}{n_{T M}}>\frac{y_{M}-\bar{y}_{T}}{\bar{y}_{T}} \\
& \frac{n_{R M}}{n_{R 2}}>\frac{\bar{y}_{R}-y_{M}}{y_{M}}
\end{aligned}
$$

Proof: See appendix.

Note that these conditions are consistent with both uniform distribution $\left(n_{T 1}=n_{T M}, n_{R M}=n_{R 2}\right)$ and non-uniform distribution. In rest of our analysis, we confine ourselves to these income distribution patterns that ensure the full market coverage in each country. Later we will discuss the implications of different cases of partial market coverage.

Following similar arguments as in the case of no intra-country income disparity, it is immediate that the MNC will charge the (uniform) prices $\bar{y}_{T} s$ and $y_{M S}$ in the Third and the rich world respectively when the markets are fully covered. These prices extract all the surpluses from the poorer buyers but leave the richer buyers with strictly positive net surpluses, and yield the ex post profit equal to $\left[\left(n_{T 1}+n_{T M}\right) \bar{y}_{T} s+\left(n_{R M}+n_{R 2}\right) y_{M S}\right]$. Maximization of this profit net of the R\&D cost gives us the following choice of innovated quality:

$$
\hat{s}_{D}^{e}=\left[\left(n_{T 1}+n_{T M}\right) \bar{y}_{T}+\left(n_{R M}+n_{R 2}\right) y_{M}\right]
$$

where, we put "hat" on the quality choice to distinguish it from the quality choice when there is no intra-country income disparity. 
Comparing (9) and (18), the following result is immediately evident:

Lemma 4: Intra-country income disparity per se lowers the level of health care innovation,

$$
\text { i.e, } \hat{s}_{D}^{e}<s_{D}^{e} \text {. }
$$

Proof: By the assumption made in (15) we can write,

$$
s_{D}^{e}-\hat{s}_{D}^{e}=n_{T}\left(y_{T}-\bar{y}_{T}\right)+n_{R}\left(y_{R}-y_{M}\right)>0
$$

Hence the claim.

Intra-country income disparity means different marginal willingness-to-pay within a country for the innovated drug. This creates scope for price discrimination among the buyers in each country only if the MNC can segment the market by offering incentive-compatible different price-quality pairs to the different types of buyers. But with zero production cost and sunk R\&D cost, such a separating menu (or price and quality discrimination) is not profitable for the $\mathrm{MNC}$ as demonstrated elsewhere [Acharyya (1998) $]^{10}$. Thus, the monopolist offers the same innovated quality to all and, under the assumption of full market coverage, sets a low uniform price for that uniform quality. To compensate for the loss of profit due to the lower (uniform) price, the MNC thus lowers the level of innovation compared to that when all buyers have the same (higher) income. What follows immediately is that a transfer of income from the rich to the poor in each country that lowers intra-country income disparity will induce a higher level of innovation under MBD. This is also apparent from (18) since $\frac{\partial s_{D}^{e}}{\partial \bar{y}_{T}}>0$ and $\frac{\partial s_{D}^{e}}{\partial y_{M}}>0$. But the changes in the intracountry income distribution pattern, as captured by the population ratios $\frac{n_{T 1}}{n_{T M}}$ and $\frac{n_{R M}}{n_{R 2}}$, have no effect on the innovation level as long as such changes satisfy (17a) and (17b) ${ }^{11}$.

\footnotetext{
10 Even though it may be difficult to conceive that a MNC will innovate an inferior quality drug, Szymanski and Valletti (2005) offer some explanations for such a possibility.

${ }^{11}$ As can be seen from the appendix, the innovation level varies among full market coverage and the three cases of partial market coverage. Thus, only if the population of Third world, say, is redistributed over the two income groups in such a way that inequality in (17a) is now reversed, the innovation level changes.
} 


\subsection{Parallel Imports, Innovation and Welfare}

Under parallel imports, given (17b) and for the relative size of the Third world large enough to induce the MNC to serve it, viz.,

$$
\frac{n_{T 1}}{n_{T M}+n_{R}}>\frac{y_{M}-\bar{y}_{T}}{\bar{y}_{T}}
$$

the global uniform price $\bar{y}_{T} s$ is charged to all consumers everywhere (see appendix). Proceeding as before, the chosen level of health-care innovation equals,

$$
\hat{s}_{P I}^{e}=\left(n_{T}+n_{R}\right) \bar{y}_{T}
$$

which is smaller than the innovation level when there is no intra-country income disparity [see eq. (11b)]. Thus, once again under the set of assumptions made in (15) and (16), intra-country income disparity per se lowers the level of innovation when all buyers are served. Moreover, from (18) and (19) it is apparent that the under-investment result holds once again: $\hat{s}_{P I}^{e}<\hat{s}_{D}^{e}$.

Comparing the equilibrium prices, on the other hand, we observe that for the low-income country the price under parallel trading is once again lower than the discriminatory price charged under MBD:

$$
\hat{P}_{P I}^{e}-\hat{P}_{D T}^{e}=\bar{y}_{T}\left(\hat{s}_{P I}^{e}-\hat{s}_{D}^{e}\right)<0
$$

The reason is the same as before. Since under parallel imports a lower quality of the innovated drug is chosen, consumers in the poor country must be charged a lower price than under MBD. Note that this result holds even when, first, the countries have the same lowest marginal willingness-to-pay, $\bar{y}_{T}$, and second, consumers are continuously distributed over an income range $\left[\underline{y}^{\prime}, \bar{y}_{j}\right]$. This is because, as we have explained earlier, the result depends more on the extent of market coverage and the innovation level than on anything else. When the poorest of the buyers in the Third World are served under both MBD and PI, as the MNC innovates a lower quality drug it must charge a lower price as well to induce them to buy the innovated drug. This possibility was overlooked in Valletti (2006) where consumers in each country are continuously and uniformly distributed over 
different income ranges, because the partial market coverage was implicitly assumed. But as Wauthy (1996) and Acharyya (1998) have demonstrated, the extent of market coverage should be an outcome of profit-maximizing behaviour of the firm(s) rather than an ex ante restriction. It can be easily checked in the simplified framework of Valletti (2006) that the parametric configurations for which the poorest country-market is always fully covered, (all) buyers there pay a lower uniform price of the innovated drug under PI than the lowest discriminatory price that they pay in absence of such parallel trading.

Regarding the consumer surplus and welfare, note that the poorest income group in the Third world has the same net surplus of zero under both the regimes, whereas the poorest income group in the rich world (those having $y_{M}$ level of income) gains from parallel imports as they now derive strictly positive net surplus. The richer income group in the Third world (those having $y_{M}$ level of income), however, unambiguously loses:

$$
\left[y_{M} \hat{s}_{P I}^{e}-\hat{P}_{P I}^{e}\right]-\left[y_{M} \hat{s}_{D}^{e}-\hat{P}_{D T}^{e}\right]=\left(y_{M}-\bar{y}_{T}\right)\left[\hat{s}_{P I}^{e}-\hat{s}_{D}^{e}\right]<0
$$

This is because the under-investment hurts them more than the price decline makes them better off as they value the quality of health-care highly. For the richest in the rich world, on the other hand, the net gain per capita from PI equals:

$$
\left[\bar{y}_{R} \hat{s}_{P I}^{e}-\hat{P}_{P I}^{e}\right]-\left[\bar{y}_{R} \hat{s}_{D}^{e}-\hat{P}_{D R}^{e}\right]=\left(n_{T}+n_{R}\right) \bar{y}_{T}+n_{R} y_{M}-n_{R} \bar{y}_{R}<0
$$

Thus, they gain from parallel trading only when their (per capita) income is smaller in the following sense:

$$
\bar{y}_{R}<y_{M}+\frac{n_{T}+n_{R}}{n_{R}} \bar{y}_{T}
$$

The intuition is simple. Under PI, the buyers gain from the lower price of the drug, but lose from a smaller innovation. Under the full market coverage, the price decline does not depend on the income (or marginal valuation) of the richest of buyers as evident from (18) - (20). But, the utility 
loss from a smaller innovation under PI, $\bar{y}_{R}\left[\hat{s}_{P I}^{e}-\hat{s}_{D}^{e}\right]$, increases proportionately with the income level. Hence, the gain in the price overcompensates the loss from lower health-care innovation for them only if their income and marginal valuation for higher innovation is not large in the sense defined in (21).

These effects are summarized in the following Lemma:

Lemma 5: With intra as well as inter country income differences, if it is profitable for the MNC to serve all markets and all consumers, parallel imports makes the poorer buyers in the Third world as well off as under MBD, the richer buyers there strictly worse off and the poorer buyers in the rich world strictly better off. The richest buyers are better off only for relatively low income or valuation as defined in (21).

Proof: Follows from the above discussion.

Since the social welfare in the Third World equals only the sum of consumer surpluses, the above result in Lemma 5 implies that parallel trading lowers the Third World welfare unambiguously. Note that the parallel exporters there earn zero profit. On the other hand, as shown in the appendix, despite gains for the buyers in the rich world, the loss of MNC-profit is so large as to lower the welfare of the rich world as well. Thus,

Proposition 2: When all countries are served for the relative country size defined in (12a), parallel import of the innovated drug from the Third to the rich world lowers the welfare of both the trading nations.

Proof: For the Third world, the adverse welfare effect follows from Lemma 5. The decline in welfare of the rich world is shown in the appendix.

This result has some far reaching implications. If the national governments put equal weights on consumer surplus and producer's profit (wherever applicable) in calculating the national welfare, and choose trade regimes for the patented drugs on that basis, neither the Third world government 
nor the rich world government will prefer parallel trading over MBD by the patent-holder MNC. This is in contrary to Richardson (2002) who demonstrated that if countries (simultaneously) choose parallel imports, global uniform pricing would be the Nash equilibrium outcome. The reason for such a Nash equilibrium obtained by Richardson is that the high-price countries that experience welfare gains from a lower (global uniform) price under parallel importing can undo price discrimination. But our Proposition 2 shows that when the adverse dynamic R\&D effect of parallel import allowed by the high-price rich world is taken into account, there is no reason for the rich world to undo price discrimination. Thus, Richardson's result does not extend to R\&D investment. At the same time, Proposition 2 shows that his second result regarding price discrimination as (Nash) equilibrium need not depend upon the ability of low-price countries to restrict parallel exports of the patented drug and hence to undo uniform pricing in this $R \& D$ case. Indeed, even if the MNC's profits are not included in the calculation of the rich country's welfare, there may be income distribution patterns in the rich country such that they still prefer price discrimination and this is of course in contrast with the no intra-inequality case we saw in the previous section.

\subsection{Partial Market Coverage and Consumer Surplus}

So far we have assumed total marked coverage both with and without MBD. Tables 1 to 4 describe the impact of parallel imports on consumer surplus of each income group under all possible partial coverage combinations. To distinguish between income earners $y_{M}$ in the Third and the rich world, we re-label their incomes as $y_{T M}$ and $y_{R M}$ respectively.

Table 1 illustrates the case when the poorest buyers in the Third world are excluded by the MNC under parallel trading. Appendix IV shows the income distribution patterns in the two countries for which such partial coverage of the Third world under parallel trading but full coverage of all markets under MBD are the equilibrium outcomes. Thus now under PI, the MNC charges the globally uniform price $y_{M} S$. Note that, in this case, the Proposition 2 holds even more strongly because the richest of the buyers in the rich world lose unambiguously from parallel imports and so do the richest in the poor country, whilst the less rich in each country are just indifferent. The intuition behind this effect is clear. As the poorest group is not served under parallel imports, the richer of the third world country lose because now all their surplus is being extracted by the MNC 
through the price $s y_{T M}$. The poorer group in the richer country already had their entire consumer surplus extracted even with MBD, just as with parallel imports now. Finally, the richest group gets a lower quality under parallel imports, not compensated by the reduced price. Thus, even without consideration for MNC location, if countries (simultaneously) choose parallel imports, MBD could arise as the Nash Equilibrium since the rich country will have no incentive to undo price discrimination. That is, in this particular case of partial coverage of the Third world under parallel trading, the Richardson's (2002) result is invalidated even when we consider only the sum of consumers' surpluses as the rich country's welfare.

Another interesting case is that described in Table 3, where MBD actually reduces the extent of market coverage (see appendix). The intuition there is that relative to the richer income group within the rich country, the $y_{R M}$ income group might be small and therefore, not covered under MBD. However, under PI, this group might be made sufficiently significant to be served by it being pulled with the $y_{T M}$ group in the poor country. This case is interesting because it is usually thought that MBD is a device to increase market coverage, but this would provide a counterexample for that. This is relevant from a policy point of view even if the whole country's welfare is still taken into account, as it is often the case that consumption of health is associated to positive externalities.

For completeness, Tables 2 and 4 present the other possible cases of partial coverage. However, in those cases consumer surplus with and without PI remains unchanged. Indeed, in the case presented in Table 2 not even the MNC's profit changes.

Table 1: Partial coverage and Richardson (2002) Result

\begin{tabular}{|l|c|c|c|}
\hline & $M B D$ & $P I$ & $C S_{P I}-S_{D}$ \\
\hline $\bar{y}_{R}$ & Covered & Covered & negative \\
\hline$y_{R M}$ & Covered & Covered & 0 \\
\hline$y_{T M}$ & Covered & Covered & negative \\
\hline $\bar{y}_{T}$ & Covered & NOT Covered & 0 \\
\hline
\end{tabular}


Table 2: The poorest buyers are not covered in either cases

\begin{tabular}{|l|c|c|c|}
\hline & MBD & PI & CSPI - CSD \\
\hline $\bar{y}_{R}$ & Covered & Covered & 0 \\
\hline$y_{R M}$ & Covered & Covered & 0 \\
\hline$y_{T M}$ & Covered & Covered & 0 \\
\hline $\bar{y}_{T}$ & NOT covered & NOT covered & 0 \\
\hline
\end{tabular}

Table 3: $M B D$ reduces market coverage

\begin{tabular}{|l|c|c|c|}
\hline & MBD & PI & CSPI - CSD \\
\hline $\bar{y}_{R}$ & Covered & Covered & Positive \\
\hline$y_{R M}$ & NOT covered & Covered & 0 \\
\hline$y_{T M}$ & Covered & Covered & 0 \\
\hline $\bar{y}_{T}$ & NOT covered & NOT covered & 0 \\
\hline
\end{tabular}

Table 4: Only the richest buyers are served under PI

\begin{tabular}{|l|c|c|c|}
\hline & MBD & PI & CSPI - CSD \\
\hline $\bar{y}_{R}$ & Covered & Covered & 0 \\
\hline$y_{R M}$ & NOT covered & NOT covered & 0 \\
\hline$y_{T M}$ & Covered & NOT covered & 0 \\
\hline $\bar{y}_{T}$ & NOT covered & NOT covered & 0 \\
\hline
\end{tabular}

\section{Partial Arbitrage: National, Regional and International Exhaustion of Property Rights}

As already discussed, the current debate on market access to new patented drugs highlights the importance of only allowing for national exhaustion of property rights so as to maximize the incentives for R\&D investment. However, although the TRIPs Agreement advocates national exhaustion (and therefore argues against parallel imports), there is an explicit reference in the 
agreement to the fact that the WTO's Dispute Settlement Understanding procedures cannot be used to implement such recommendation. Moreover, under the Doha declaration on TRIPs and public health, all WTO members are explicitly allowed to use international exhaustion, and therefore, import cheaper medicines from other countries, if they do not have own production facilities and there is an issue of public health on the line. Still, a considerable number of developed countries, including the EU members, and even, more recently, the high income developing countries (Hong Kong China, Israel, Korea, Kuwait, Macao China, Mexico, Qatar, Singapore, Chinese Taipei, Turkey, United Arab Emirates) have agreed to only use such system in case of national emergencies or other circumstances of extreme urgency ${ }^{12}$. At the same time, groups of developed countries such as EU members apply a rule of regional exhaustion at the EU level (whereby parallel imports cannot be prevented within the EU) and the US is considering parallel trade from other developed countries such as Canada and the EU.

In this section, we investigate price discrimination between blocks of countries in a way that would reflect the above debate. A fairly straightforward way of presenting this in the context of the current model would be to reinterpret our two country setting with within country income disparities as a two two-country block model, a first block with a richer and a middle income country $\left(\bar{y}_{R}\right.$ and $y_{M}$ respectively) and a second block with a middle and a lower income country ( $y_{M}$ and $\bar{y}_{T}$ respectively). Now, our benchmark would be the case with the international exhaustion of property rights, in this case, parallel imports are allowed across all countries and there is a unique world price. This case corresponds to the analysis in section 3.2. A second possibility would be for the world to be divided in these two blocks of countries where only regional exhaustion applies, that is, parallel imports are allowed within but not between blocks and therefore there is scope for price discrimination between blocks. This case corresponds to the case analyzed in section 3.1. Finally, and possibly the closest case to reality would be to consider the regional exhaustion being implemented in the wealthier block (we could think of it as the EU), whereas only national exhaustion applies everywhere else. That is, the pharmaceutical MNC cannot price discriminate across the developed countries (it must set a single EU price) but, it can price discriminate between the out of the EU developing countries. This case would match our previous

\footnotetext{
${ }^{12}$ See www.wto.org for a detailed description of this provision.
} 
discussion. This possibility is half way between the two other cases already analyzed. In this case, the MNC will charge price $\bar{y}_{T} s$ in the poorest country and price $y_{M} s$ everywhere else. Of course, the underlying assumption is that the poorest country in the EU-bloc (the country with per capita income level $y_{M}$ ) is large enough in size relative to the richest country in the bloc in the sense defined in (17b) that makes it profitable for the MNC to serve both these EU countries (which we may call full EU coverage $)^{13}$. Note that the difference with the discrimination between blocks (second case above) is that now the richer country outside the EU also faces price $y_{M} s$ and that the optimal quality will be higher since the higher marginal wiliness to pay for quality of this country is now being captured by the multinational.

We can, therefore, ask ourselves, initially taking one world price as the benchmark, would countries prefer to move on to a system of regional exhaustion blocks (section 3.1) or a system where regional exhaustion applies only to the developed countries (EU) block? The answer will be different for every country type. Starting with the poorest country type $\bar{y}_{T}$ (assuming coverage of all the markets in all the cases), this country will actually be indifferent between going from one world price to any of the other two systems as in every case their full consumer surplus is extracted. Regarding the poorer country in the EU block, they are just as unhappy about moving away from one world price to any of the other two systems as in both cases their full consumer surplus will now be extracted (when all the markets are served in all the cases).

The difference now comes for the other two types of countries. The richer country outside of the EU will clearly prefer a system of regional blocks (developed and developing) as in that case it would pay a lower price (once again under the assumption that all markets are served) since the MNC would not be able to discriminate between it and the poorest country. Therefore, if richer countries out of the EU commit to not use parallel imports, they will eventually give up all their consumer surplus as a result and, unlike in the case of two regional blocks, they would actually prefer a one world price (worldwide parallel imports) to this situation as in this case the quality increase does not compensate for the price increase.

\footnotetext{
${ }^{13}$ Otherwise, there would be the prices $s \bar{y}_{T}$ and $s y_{M}$ for the two countries outside the EU and $\mathrm{s} \bar{y}_{R}$ for the EU bloc (which denies market access for the poorest EU country under this particular TRIPS arrangement).
} 
Finally, we have the richest country in the EU who will indeed be happier about keeping regional exhaustion in the EU and out of the EU countries to commit to not allow parallel imports. The reason is that it still benefits from lower prices brought by an internal price arbitrage but now, as the MNC extracts more consumer surplus from out of the EU middle-income countries, the equilibrium quality will be higher.

We can then conclude that only the richest countries strictly benefit from the latest commitment of out of the EU middle-income countries not to allow parallel imports, with the lower income countries within the EU and the poorest world country being indifferent albeit enjoying a higher quality. It is worth reminding though that the highest incentives to innovate would be achieved when the MNC can fully price discriminate across all countries.

Of course, a similar conclusion can be deduced if we allow for income disparity in each of these countries as long as the ranking of the equilibrium prices under these alternative regional and national exhaustion regimes remains the same.

\section{Conclusion}

We have shown in terms of a very simple analytical framework that regardless of any intra country income differences, parallel imports result in a lower level of health-care innovation but, contrary to popular as well as conventional theoretical wisdom, a lower price in the third world compared to market-based discrimination. Despite such a lower price, however, parallel imports unambiguously make all buyers in the Third world worse off when intra-country income disparity exists. The only gainers from parallel imports appear to be the buyers in the rich world. But with the MNC-profit declining the rich world unambiguously loses. This leaves open the question why do countries often allow parallel trading, and points to the observations by Maskus (2005) and others that there may be considerations other than welfare.

Malueg and Schwartz (1994) present a variation of their model structure in which demand types are placed into groups and price arbitrage is only possible across groups. They state that if demand dispersion is low enough to ensure that all demand types would always be served at some prices, 
the uniform pricing would result in the same welfare as price discrimination across these groups. The reinterpretation of our model structure in section 4 above is motivated along the same line. But, contrary to Malueg and Schwartz (1994), we find that with endogenous quality, price discrimination is actually superior to uniform pricing and indeed we can also say that no group within society would strictly prefer uniform pricing. 


\section{Appendix:}

\section{Proof of Lemma 3:}

Let $\pi_{D}, \tilde{\pi}_{D}, \widetilde{\pi}_{D}$, and $\hat{\pi}_{D}$ denote profits of the MNC when all buyers in all markets are served (i.e., full coverage of all markets), only rich buyers in the Third world and all buyers in the rich world are served, all buyers in the Third world but only rich buyers in the rich world are served, and only the rich buyers in each country are served respectively. Proceeding as in the text, the following values of these profits can be easily checked:

$$
\begin{aligned}
& \pi_{D}=\left[n_{T} \bar{y}_{T}+n_{R} y_{M}\right]^{2} / 2 \\
& \left.\tilde{\pi}_{D}=\left[\left(n_{T M}+n_{R}\right) y_{M}\right)\right]^{2} / 2 \\
& \tilde{\pi}_{D}=\left[n_{T} \bar{y}_{T}+n_{R 2} \bar{y}_{R}\right]^{2} / 2 \\
& \hat{\pi}_{D}=\left[n_{T M} y_{M}+n_{R 2} \bar{y}_{R}\right]^{2} / 2
\end{aligned}
$$

Thus, given the full market coverage in the rich world, all buyers in the Third world are served if $\pi_{D}$ $>\tilde{\pi}_{D}$. From (A.1) and (A.2) it can be checked that this is satisfied for condition (17a) in the text, viz., $\frac{n_{T 1}}{n_{T M}}>\frac{y_{M}-\bar{y}_{T}}{\bar{y}_{T}}$. On the other hand, given full market coverage in the Third world, the MNC will prefer to cater all buyers in rich country if $\pi_{D}>\widetilde{\pi}_{D}$, which boils down to the condition (17b), viz., $\frac{n_{R M}}{n_{R 2}}>\frac{\bar{y}_{R}-y_{M}}{y_{M}}$. In other words, under these income distribution patterns, the MNC would prefer to cater "all" buyers to "some" buyers in one country and all buyers in the other.

Finally, note that since the richest buyers in the Third world and the poorest buyers in the rich world have the same income level $y_{M}$, so the same condition (17b) ensures that $\tilde{\pi}_{D}>\hat{\pi}_{D}$. Therefore, if the income distribution patterns in the two countries satisfy these two conditions, then

$$
\begin{aligned}
& \pi_{D}>\tilde{\pi}_{D} \\
& \pi_{D}>\tilde{\pi}_{D}>\hat{\pi}_{D}
\end{aligned}
$$

That is, the MNC serves all buyers everywhere under MBD. 
Since profit in each of these cases is equal to half the squared value of the innovated quality level, so the innovation by the MNC under MBD varies with the income distribution pattern. Under conditions (17a) and (17b), the innovation level is the highest.

\section{Formal derivation of condition (12.a)}

There are three pricing and market coverage options for the MNC under Parallel Imports (PI):

Possibility 1 realizing a profit of $\pi_{1}$ : serve all markets and all buyers by charging the price $\bar{y}_{T} \mathrm{~s}$

Possibility 2 realizing a profit of $\pi_{2}$ : serve all markets and all buyers except the poorest one in the Third world by charging the price $\mathrm{sy}_{\mathrm{M}}$

Possibility 3 realizing a profit of $\pi_{3}$ : serve only the richest in the rich world by charging the price

$$
\bar{y}_{R} \mathrm{~S}
$$

We call possibility 1 as the full (global) market coverage.

Now it is straightforward to check that $\pi_{2}>\pi_{3}$ for $\frac{n_{R M}+n_{T M}}{n_{R 2}}>\frac{\bar{y}_{R}-y_{M}}{y_{M}}$. Condition (17b) for full coverage of the rich-world market under MBD, i.e.,

$$
\frac{n_{R M}}{n_{R 2}}>\frac{\bar{y}_{R}-y_{M}}{y_{M}} \text { ensures this. }
$$

So given (17b), for full (global) market coverage (that is possibility 1 ) under PI all we need to check is whether $\pi_{1}>\pi_{2}$. And the following condition ensures this:

$$
\frac{n_{T 1}}{n_{T M}+n_{R}}>\frac{y_{M}-\bar{y}_{T}}{\bar{y}_{T}}
$$

\section{Welfare of the Rich World under full market covergae}

Let $W_{i}^{R}$ denote the welfare of the rich world under regime $\mathrm{i}=\mathrm{D}, \mathrm{PI}$, which is the sum of consumers surplus, $S_{i}^{R}$, and the MNC profit. Hence,

$$
W_{D}^{R}-W_{P I}^{R}=\left(n_{R M} y_{M}+n_{R 2} \bar{y}_{R}\right)\left(\hat{s}_{D}^{e}-\hat{s}_{P I}^{e}\right)+\left(n_{T 1}+n_{T M}\right)\left(\hat{P}_{D T}^{e}-\hat{P}_{P I}^{e}\right)+\frac{1}{2}\left[\left(\hat{s}_{P I}^{e}\right)^{2}-\left(\hat{s}_{D}^{e}\right)^{2}\right]
$$


This after simplification boils down to,

$$
\begin{aligned}
W_{D}^{R}-W_{P I}^{R} & =\frac{1}{2}\left[n_{R M} y_{M}+n_{R 2}\left(2 \bar{y}_{R}-y_{M}\right)-\left(n_{R M}+n_{R 2}\right) \bar{y}_{T}\right]\left(\hat{s}_{D}^{e}-\hat{s}_{P I}^{e}\right) \\
& =\frac{1}{2}\left[n_{R M}\left(y_{M}-\bar{y}_{T}\right)+n_{R 2}\left(\bar{y}_{R}-y_{M}\right)+n_{R 2}\left(\bar{y}_{R}-\bar{y}_{T}\right)\right]\left(\hat{s}_{D}^{e}-\hat{s}_{P I}^{e}\right)>0
\end{aligned}
$$

\section{Partial Market Coverage:}

From Appendices I and II above, we can identify parametric configurations that determine the extent of coverage of each market. Let $\theta_{T} \equiv \frac{y_{M}-\bar{y}_{T}}{\bar{y}_{T}}$ and $\theta_{R} \equiv \frac{\bar{y}_{R}-y_{M}}{y_{M}}$ denote the (relative) income disparity in the Third world and in the rich world respectively. The following figures then illustrate different possibilities.

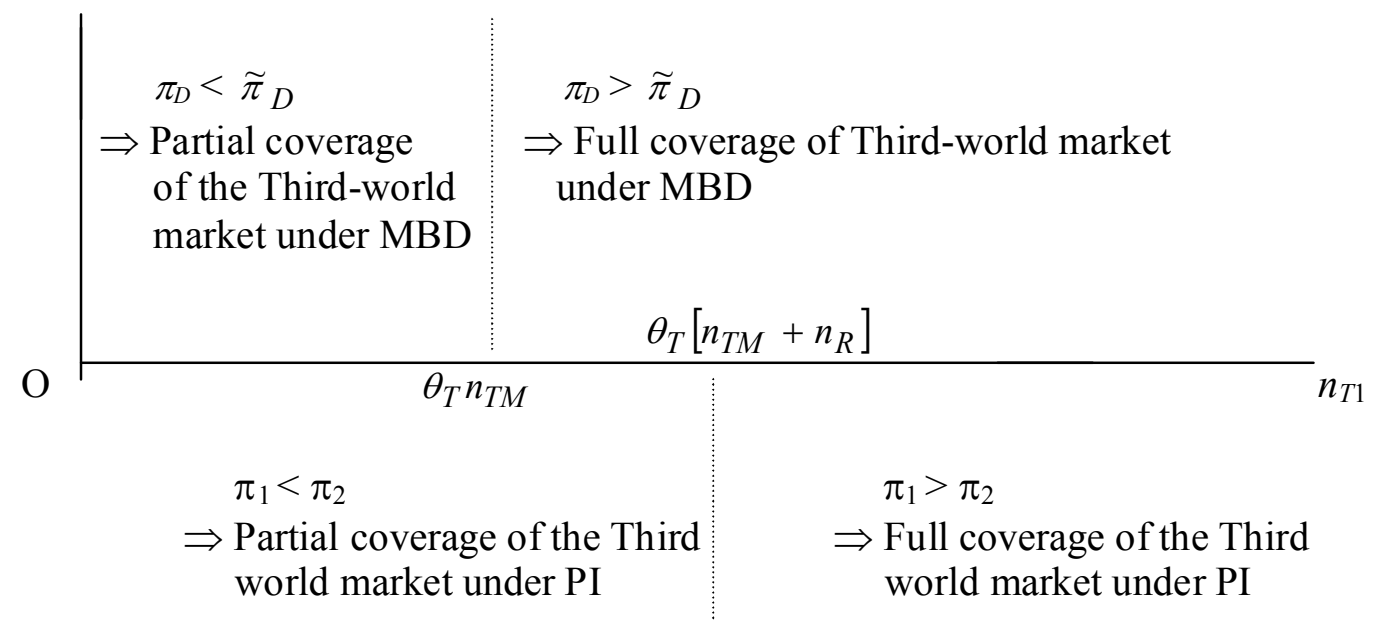

Figure 1: Third World Market Coverage given full coverage of Rich World 


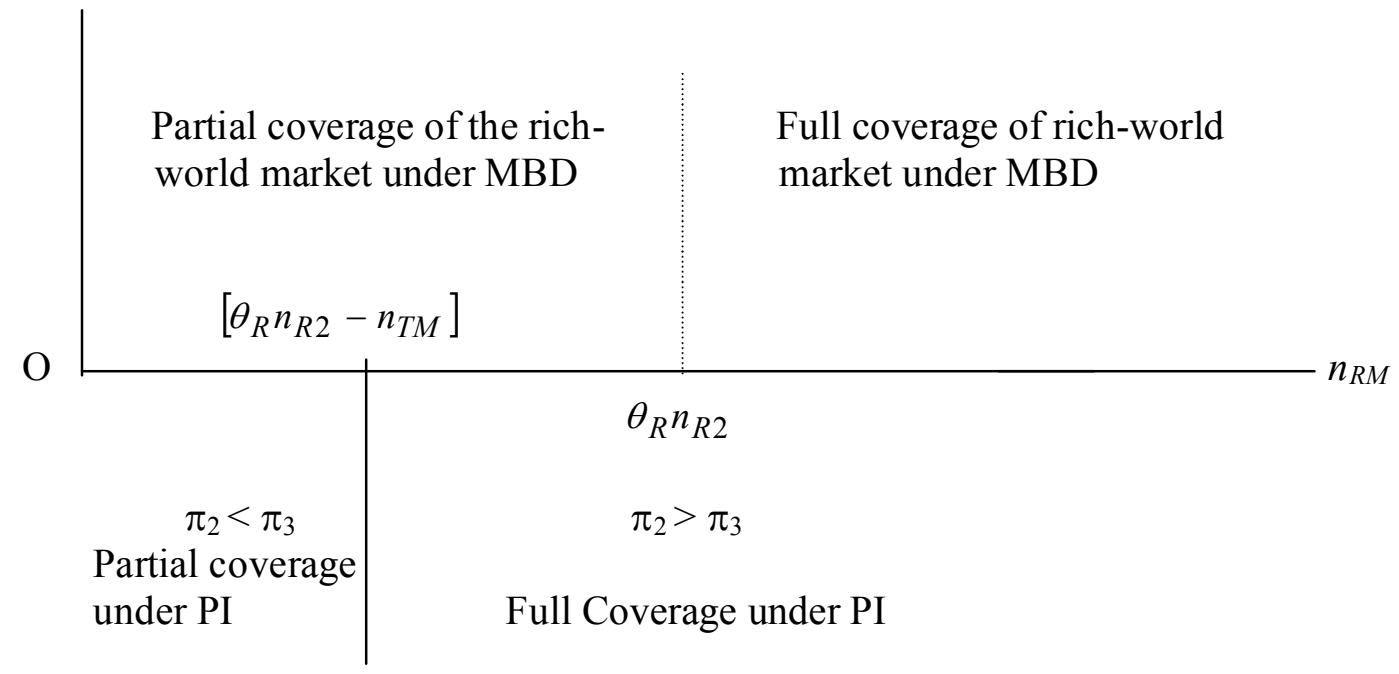

Figure 2: The Extent of the Rich World Market Coverage

Now, suppose

$$
\begin{aligned}
& n_{T 1} \in\left[\theta_{T} n_{T M}, \theta_{T}\left(n_{T M}+n_{T R}\right)\right] \\
\text { and } \quad & n_{R M}>\theta_{R} n_{R 2}
\end{aligned}
$$

The latter is in fact the condition $(17 \mathrm{~b})$ in the text.

Then, the Third-world market is partially served whereas the rich-world market is fully served under PI because $\pi_{1}<\pi_{2}$ and $\pi_{2}>\pi_{3}$ in such a case (see appendix II above). However, all buyers everywhere is served under MBD even with such a size of the poorest buyers in the Third-world since (17a) still holds. The welfare property of this case is discussed in Table 1 in the text.

The case in which MBD reduces market coverage, as discussed in Table 3 in the text, on the other hand, arises under the following parametric configuration:

$$
\begin{aligned}
& n_{T 1}<\theta_{T} n_{T M} \\
& n_{R M} \in\left[\theta_{R} n_{R 2}-n_{T M}, \theta_{R} n_{R 2}\right]
\end{aligned}
$$


Once again, the Third-world market is partially served whereas the rich-world market is fully served under PI because $\pi_{1}<\pi_{2}$ and $\pi_{2}>\pi_{3}$ for these parametric configurations. Under MBD, on the other hand, since both the conditions (17a) and (17b) are violated, only the richer buyers in each country-markets are served. Hence, MBD lowers the extent of (global) market coverage. 


\section{References:}

Acharyya, R., 2005, Product Standards, Employment and Exports: An Analytical Study, Physica/Springer Verlag: Heidelberg.

Acharyya, R., 1998, “Monopoly and Product Quality: Separating or Pooling Menu?" Economics Letters, 61: 187-94.

Acharyya, R. and M. Garcia-Alonso, 2006, "Self-interested motives for income redistribution and access to health care innovation", European Journal of Political Economy, 22(2): 322-36.

Abbott, F., 1998, "First Report (Final) to the Committee on International Trade Law of the International Law Association on the Subject of Parallel Importation", Journal of International Economic Law 1: 607-636.

Cooper, R., 1984, “On allocative distortions in problems of self-selection”, Rand Journal of Economics 15: 569-77.

Danzon, P.M., 1998, "The economics of parallel trade", Pharmacoeconomics 13: 293-304.

Hornbeck, R. A., 2005, "Price discrimination and smuggling of AIDS drugs", Topics in Economics Analysis and Policy, 5: 1-25.

Jelovac, I. and C. Bordoy, 2005, "Pricing and Welfare Implications of Parallel Imports in the Pharmaceutical Industry", International Journal of Health Care Finance and Economics, 5: 5-21.

Malueg, D.A., and M. Schwartz, 1994, "Parallel imports, demand dispersion and international price discrimination", Journal of International Economics 37: 167-196.

Maskus, K., 2001, "Parallel imports in Pharmaceuticals: Implications for competition and prices in developing countries", Final Report to World Intellectual Property Organization.

Mussa, M. and S. Rosen, 1978, "Monopoly and product quality”, Journal of Economic Theory, 18: 301-17.

Nelson, P., 1974, “Advertising as information”, Journal of Political Economy (July/August), 72954.

Richardson, M., 2002, “An elementary proposition concerning parallel imports”, Journal of International Economics 56: 233-45.

Rovira, J., 2002, "The pricing of pharmaceuticals in low-income countries", European Journal of Health Economics 3: 223-225.

Shaked, A. and J. Sutton, 1982, "Relaxing price competition through product differentiation", Review of Economic Studies, 49: 3-13. 
Sherer, F.M. and Watal, J., 2002, "Post-trips options for access to patented medicines in developing nations", Journal of International Economics Law 913-939.

Tirole, J., 1989, Theory of Industrial Organization, MIT Press.

Valletti, T.M., 2006, "Differential pricing, parallel imports and the incentive to invest", Journal of International Economics 70: 314-24.

Wauthy, X., 1996, "Quality choice in models of vertical differentiation", Journal of Industrial Economics, 65: 345-53. 